\title{
Prolonged Remission of Prostate Cancer Presenting as Endobronchial Metastases Following Total Androgen Blockade: A Case Report and Literature Review
}

\author{
Robert S. Freund ${ }^{a} \quad$ Peter V. Pickens ${ }^{b}$ John Z. McDonald \\ Robert D. Mino ${ }^{b}$

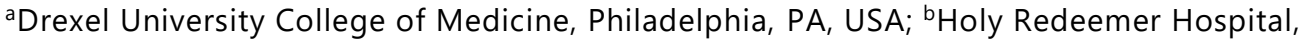 \\ Meadowbrook, PA, USA
}

\section{Keywords}

Metastatic prostate cancer - Endobronchial metastases - Androgen blockade $\cdot$ Remission

\section{Abstract}

We present a rare case of prostatic endobronchial metastases that was successfully treated with total androgen blockade (TAB). This case demonstrates prolonged remission on continuous TAB and continued remission employing intermittent therapy. 


\section{Case Reports in Oncology}

\section{Introduction}

Prostate cancer presenting as endobronchial metastases is rare as evidenced by only 22 reports in the literature as of 2019 [1-11]. Survival with metastatic prostate cancer with distant metastases is generally poor with 5-yr survival rates of $30.5 \%$ according to the Seer database [12]. Median survival following diagnosis of endobronchial metastases from any extrathoracic cancer has ranged from 15.5-16.1 months [13]. A Korean study of all patients detected to have endobronchial metastases on biopsy at one institution over an 18-yr span showed a median survival from diagnosis of 5 months for 2 patients diagnosed with metastatic prostate cancer to the endobronchus [13]. Long term follow after diagnosis of prostatic carcinoma with endobronchial metastasis is absent from the literature with the longest previously documented survival, to our knowledge, being 13 months [7]. We present 18-yr survival in a patient with confirmed endobronchial metastases from an earlier primary prostate cancer.

\section{Case Presentation}

A 55-year-old Caucasian male presented in 1990 with Stage pT3b N0 MX moderately-differentiated carcinoma of the prostate with seminal vesicle involvement. Patient had radical retropubic prostatectomy (RPR) performed with bilateral pelvic lymph node dissection (BPLND). He declined adjuvant therapy following therapy, and at 1-year post-op he had salvage external radiation therapy (XRT) for a pelvic nodule.

Patient presented 9 years later in July 1999 at 63-years-old with cough, dyspnea, and 1 episode of massive hemoptysis without chest pain. On physical exam, patient was anicteric. There was no lymphadenopathy. Chest exam was unrevealing with no dullness to percussion, rub, or wheezing. Heart had easily audible S1 and S2. Liver was normal in vertical span. No spleen or abdominal mass was present. Chest CT with contrast showed a right middle lobe and hilar mass. Bronchoscopy demonstrated endobronchial disease traversing the carina, and biopsy of the right middle lobe and left carina showed poorly-differentiated, non-small cell carcinoma consistent with metastases from prostatic carcinoma. Immunohistochemical stain of the tumor showed positive immunoreactivity to PSA. The specimens demonstrated negative immunoreactivity to thyroid-transcription factor-1 (TTF-1) and were negative for intraplasmic mucin and prostatic specific acid phosphatase. Serum PSA was $425.3 \mathrm{ng} / \mathrm{mL}$. Bone scan was consistent with the new appearance of metastatic disease as indicated by foci of increased activity in the mid-thoracic spine, ribs, and pelvis.

Patient was prescribed total androgen blockade, employing q 3 month depot leuprolide and flutamide $250 \mathrm{mg}$ PO tid. On follow-up his PSA dropped precipitously from $425 \mathrm{ng} / \mathrm{mL}$ initially to $40.4 \mathrm{ng} / \mathrm{mL}$ at $1 \mathrm{month}, 5.8 \mathrm{ng} / \mathrm{mL}$ at two months and $1.0 \mathrm{ng} / \mathrm{mL}$ at 3 months. His cough, dyspnea and hemoptysis resolved. Repeat chest CT revealed virtual complete resolution of mediastinal adenopathy showing subtle residual hilar mass or adenopathy on right and some persistent localized volume loss or scarring of the right middle lobe.

Patient continued on androgen blockade. PSA has been undetectable at $<0.1 \mathrm{ng} / \mathrm{mL}$ since October 2000. Patient replaced depot leuprolide with q 3 month depot goserelin $10.8 \mathrm{mg}$ in 2003 , but he continued flutamide. Bone scan performed on July 2003 showed resolution of 
prior metastatic bone lesions. Chest CT was repeated in 2013 and noted the absence of parenchymal nodules or mass in either lung, as well as the absence of axillary, mediastinal, or hilar lymphadenopathy.

At patient's request and in consideration of recent literature, androgen blockade was discontinued in October 2014 due to fatigue [14]. Fatigue markedly improved following cessation of androgen deprivation.

As of April 2019, it has been 18 years total the patient has remained in biochemical and clinical remission, with the last 5 years without androgen blockade. PSA has continued to be undetectable at $<0.1 \mathrm{ng} / \mathrm{mL}$. Patient continues to deny pulmonary symptoms including cough, shortness of breath and hemoptysis. Patient's quality of life is excellent.

\section{Discussion}

Prostate cancer presenting as endobronchial metastasis is uncommon as supported by our review of the literature. In total we identified 23 reports of patients, including this case, presenting with prostatic endobronchial metastases (Table 1). The mean age at presentation was 70 years. Including our case, there are 9 cases documented with an extended time interval between primary tumor diagnosis and diagnosis of endobronchial metastases. The longest documented interval was 20 years [2]. Our case has an interval of 9 years. Hemoptysis or cough were the most common presenting symptoms each occurring at rates of $35 \%(8 / 23)$ and $40 \%$ ( $9 / 23$ patients) respectively. In consideration of these findings, prostatic endobronchial metastases should be included on the differential for patients with nonspecific symptoms of cough or hemoptysis, especially if the patient has a history of primary prostate cancer, even if it is remote. In addition, due to the infrequency of this condition it is appropriate to document patients' clinical course for future study.

Our case presentation demonstrates that successful treatment and long-term remission is possible for metastatic prostate carcinoma with endobronchial metastases. Prognosis for endobronchial metastases is dependent on the tissue of origin, but prognosis is generally poor [13]. TAB was the standard of care for metastatic prostatic cancer in 1999 and remains a key component of treatment [15].

Additionally, recent literature has shown that intermittent androgen deprivation is noninferior, in terms of survival, to continuous therapy and allows for minimization of side effects [14]. Our case supports this approach for prostatic endobronchial metastases with our patient's continued 5-year biochemical and clinical remission following cessation of TAB.

\section{Acknowledgements}

None. 


\section{Case Reports in Oncology}

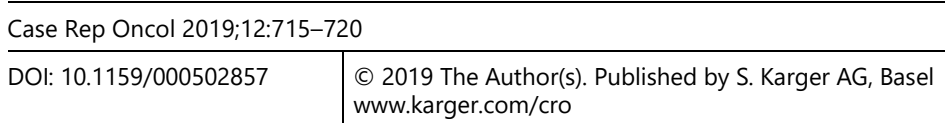

Freund et al.: Prolonged Remission of Prostate Cancer Presenting as Endobronchial Metastases Following Total Androgen Blockade

Statement of Ethics

This research was conducted ethically in accordance with the World Medical Association Declaration of Helsinki. The subject has given their written informed consent to publish their case.

\section{Disclosure Statement}

The authors have no conflicts of interest to declare.

\section{Funding Sources}

Publication of this work was supported by the Abington Health Foundation. The funder had no role in study design; in the collection, analysis and interpretation of data; decision to publish; or in preparation of the manuscript.

\section{Author Contributions}

R.S. Freund conducted the literature review, drafted the manuscript, and was involved in clinical follow-up. P.V. Pickens edited the manuscript and was involved in execution and development of the theuraputic plan, as well as clinical follow-up. R.D. Mino was involved in patient evaluation, theuraptic plan, and treatment. J.Z. McDonald was involved in patient evaluation and clinical follow-up. All authors critically reviewed and approved the final manuscript.

\section{References}

1 Asghar Nawaz M, Shackcloth M. Unusual endobronchial prostatic metastatic tumor occluding right main bronchus. Asian Cardiovasc Thorac Ann. 2019 Mar;27(3):228-30.

2 Hatakeyama Y, Yoshimura S, Ninomaru T, Fujimoto S, Takamiya R, Okamura K, et al. Endobronchial metastases 20 years after prostate cancer excision. Respir Med Case Rep. 2019 May;27:100858.

3 Hotta T, Tsubata Y, Kodama A, Mori Y, Nakao M, Amano Y, et al. A case of multiple endobronchial metastasis from prostate cancer showing good response to chemotherapy. Journal of the Japan Society for Respiratory Endoscopy. 2017;39:262-7.

4 Bonney A, Bowden P, Antippa P, Steinfort D. Endobronchial Prostate Metastasis. J Bronchology Interv Pulmonol. 2017 Jan;24(1):e1-3.

5 Kim R, Nidadavolu V, Pfister G, El-Kersh K, Gauhar U. C80 THORACIC ONCOLOGY: CASE REPORTS: Endobronchial Metastasis In A Patient With Adenocarcinoma Of The Prostate. Am J Respir Crit Care Med. 2016;193:1.

6 Martinez J, Albors-Sanchez J, Rodriguez-Cintron W. C80 THORACIC ONCOLOGY: CASE REPORTS: An Unusual Endobronchial Lesion. Am J Respir Crit Care Med. 2016;193:1.

7 Shen Q, Yao Y, Teng X, Zhou J. Endobronchial metastasis from prostate cancer mimicking primary lung cancer. Intern Med. 2010;49(15):1613-5.

8 Lee JE, Lee YJ, Jeong MK, Park HS, Jung SS, Kim JO, et al. A case of multiple endobronchial metastases from prostatic carcinoma. Tuberc Respir Dis (Seoul). 2006;61(2):162-6. 
9 Kwon DY, Seo CG, Kim BS, Kwak JH, Kim MS, Choi WI, et al. A case of endobronchial metastasis from prostatic cancer. Tuberc Respir Dis (Seoul). 2000;49(4):502-7.

10 Pérez MM, i Ribas CD, Acín JS, Cueto RB, Pérez AM. i Ribas CD, Acín JS, Cueto RB, Pérez AM. Bilateral Endobronchial Metastases from Adenocarcinoma of the Prostate. Journal of Bronchology. 1995;2(4):304-7.

11 Taylor H, Braude S. Lobar collapse due to endobronchial metastatic prostatic carcinoma: re-expansion with antiandrogen treatment. Thorax. 1990 Jan;45(1):66-7.

12 Howlader N, Noone AM, Krapcho M, Miller D, Brest A, Yu M, et al., editors. SEER Cancer Statistics Review, 1975-2016, National Cancer Institute. Bethesda, MD, https://seer.cancer.gov/csr/1975_2016/, based on November 2018 SEER data submission, posted to the SEER web site, April 2019.

13 Lee SH, Jung JY, Kim DH, Lee SK, Kim SY, Kim EY, et al. Endobronchial metastases from extrathoracic malignancy. Yonsei Med J. 2013 Mar;54(2):403-9.

14 Magnan S, Zarychanski R, Pilote L, Bernier L, Shemilt M, Vigneault E, et al. Intermittent vs Continuous Androgen Deprivation Therapy for Prostate Cancer: A Systematic Review and Meta-analysis. JAMA Oncol. 2015 Dec;1(9):1261-9.

15 Sartor O, de Bono JS. Metastatic Prostate Cancer. N Engl J Med. 2018 Feb;378(7):645-57. 
Table 1. Case reports documenting prostatic endobronchial metastasis*

\begin{tabular}{|c|c|c|c|c|}
\hline Authors [Ref.], year & $\begin{array}{l}\text { Age, } \\
\text { years }\end{array}$ & $\begin{array}{l}\text { Presenting } \\
\text { symptoms }\end{array}$ & $\begin{array}{l}\text { Length of } \\
\text { survival at } \\
\text { last follow-up }\end{array}$ & $\begin{array}{l}\text { Time interval between } \\
\text { diagnosis of primary } \\
\text { tumor and diagnosis of } \\
\text { endobronchial metastasis }\end{array}$ \\
\hline Current case & 63 & Cough, hemoptysis, dyspnea & 18 years & 9 years \\
\hline Nawaz et al. [1], 2019 & 80 & Dyspnea & - & - \\
\hline Hatakeyama et al. [2], 2019 & 78 & Cough, chest pain, weight loss & - & 20 years \\
\hline Hotta et al. [3], 2017** & 67 & Cough, dyspnea & - & Concurrent diagnosis \\
\hline Bonney et al. [4], 2017 & 67 & Asymptomatic & - & 3 years \\
\hline Bonney et al. [4], 2017 & 77 & Asymptomatic & - & 10 years \\
\hline Kim et al. [5], 2016 & 68 & Hemoptysis & - & - \\
\hline Martinez et al. [6], 2016 & 80 & Chest pain & - & - \\
\hline Shen et al. [7], 2010 & 72 & Asymptomatic & 13 months & Concurrent diagnosis \\
\hline Garai et al. [3], 2010 & 84 & Hemoptysis, weight Loss & - & Concurrent diagnosis \\
\hline Gerogianni et al. [3], 2008 & 64 & Cough, dyspnea & - & 5 years and 5 months \\
\hline Lee et al. [8], 2006 & 74 & Cough & - & - \\
\hline Yamada et al. [3], 2004 & 67 & - & - & Concurrent diagnosis \\
\hline Takahashi et al. [3], 2001 & 73 & Hemoptysis & - & Concurrent diagnosis \\
\hline Kwon et al. [9], 2000 & 78 & Cough & - & - \\
\hline Pérez et al. [10], 1995 & 72 & Hematuria & - & Concurrent diagnosis \\
\hline Egawa et al. [3], 1993 & 63 & Cough, dyspnea & - & Concurrent diagnosis \\
\hline Lee et al. [3], 1990 & 78 & Hemoptysis & - & 3 years \\
\hline Helena et al. [11], 1990 & 81 & Hemoptysis, dyspnea & - & 1 year and 7 months \\
\hline Kenny et al. [3], 1988 & 59 & Hemoptysis, dyspnea & - & Concurrent diagnosis \\
\hline Scherz et al. [3], 1986 & 67 & - & - & 7 years \\
\hline Lalli et al. [3], 1983 & 55 & Cough, hemoptysis & - & Concurrent diagnosis \\
\hline Scoggins et al. [3], 1978 & 58 & Cough & - & 4 years \\
\hline
\end{tabular}

* We performed an extensive review of the English language literature using the databases of PubMed Central, Web of Science, Cochrane Library, and Google Scholar with keywords of ("prostate" or "prostatic,") and ("endobronchus" or "endobronchial") and ("metastases" or "metastatic" or "metastasis"). We also reviewed references of relevant papers. NonEnglish publications were included in the count, if the age at presentation and disease entity could be substantiated by an English language abstract or reference from another journal. Retrospective reviews or post-mortem cases were not included. Data was unavailable for boxes marked with the dash: "-" symbol.

** Select case reports appearing in Table 1 are cited under Hotta et al. [3] rather than individually referencing each case. Hotta et al. previously documented these cases in their literature review. 